\title{
The Virtual School of Architecture and Design
}

\author{
M. C. G. O. Holland \\ School of Architecture and Urbanism, Cruzeiro do Sul University, Brazil \\ MCG Art-Education, Research Department, Brazil
}

\begin{abstract}
The Virtual School of Architecture and Design - VS - is an innovative 3-D virtual environment. The environment was created to provide the perception of an advanced "real" school of architecture. The studios, laboratories, library, classrooms, galleries, theatre and movies were designed with "learning objects" and other advanced tools. There are interactive spaces to develop intellectual and creative skills. The activities are designed to integrate concepts and practices in the architecture field with an interdisciplinary curriculum: Humanism, Technology, Creativity and Innovation.

Keywords: digital architecture, virtual school of architecture, online education, e-learning, Creativity and Interactions online.
\end{abstract}

\section{Introduction}

Digital Technologies are revolutionizing the practices of teaching and learning at universities all around the world. For decades now architects have struggled with how best to address the needs of students. Interdisciplinary studies and collaborative design in education promote significant changes to architects and educators. Technology and the integration of internet and multimedia offer teachers a tremendous opportunity to put their students in touch with other cultures, a well as to teach them how to manager information: collecting, analyzing, interpreting and presenting data. Powerful simulation engines will present verisimilitude to educational experiences that is unavailable in twentiethcentury schools. Students will be able to test sophisticated designs and hypotheses or verify details like architectural forms and natural illumination, colour system or understand complex urban structure.

Like a real university, the Virtual School of Architecture and Design - VS presents qualified spaces, interaction and administrative resources. 


\section{The Virtual School of Architecture and Design - VS}

The Virtual School of Architecture and Design - VS - is an innovative 3-D virtual world. The environment was created identifying discrepancies between courses online and the special needs to attend architecture area, in particular creativity and expressive development spaces.

\subsection{The simulation}

Simulations are coming of age. The Virtual School of Architecture and Design VS - was designed as a creative space with studios, classrooms, laboratories, library, galleries, theatre, movies and a special self knowledge centre to improve differentiating curricula and develop personal skills. The spaces were concept in linear, cyclical, open, and open-ended modes. Linear mode suggests spaces where the students will watch videos, films and clips or read articles, case studies, texts, and e-books. Cyclical mode was applied to attend repetitive actions in order to provide complex understandings about phenomena. For example, students understanding theory of colour light at colorimetric laboratory. The lab has three different fonts (red, green and blue), fig 1 . The student will learn how to obtain many colours with additive synthesis addicting more or less luminosity. To represent faithfully, this activity was linked to a real problem or case and the content can transfer to real life immediately. Open mode content was designed to creative spaces, studios of design, ateliers. The activity doesn't require attending a goal. The problem is presented and you can solve by hundreds and unrestricted solutions. Open-ended mode was applied to design spaces with multivariate cases involving several keys variables. The students solve problems relating knowledge and strategies. For example: urbanism and planning laboratory (multiple keys and variables).

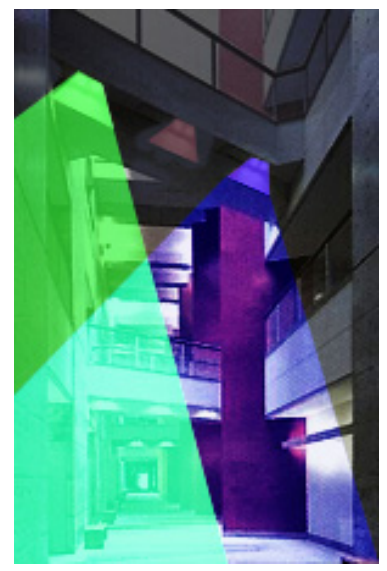

Figure 1: VS. Laboratory of Colour: mixing lights. 


\subsection{Metaphor of Architecture and Modelling Spaces}

To build metaphor references, the architecture style remembers the real world. In many situations the space presents new visual codes and modern syntaxes because they must be very attractive and dynamic in order to motivate students. The subject is architecture so everybody, students and teachers hope other sensations and coherences at virtual space, especially in web design. The Virtual School of Architecture and Design - VS - was developed to give correct perceptions. Starting with the transformation of the usual entrance hall and its combination with types of typologies, the main entrance was built to encourage people to have experiences with art and architecture, fig. 2. But once inside the atrium students can go to art gallery, theatre, movies, auditorium and coffee shop. The pronounced presence of natural light is a lesson about sustainable and ecology architecture. Paradox is used to make what is invisible, visible and the presence of past and present models. Placed around the central building were located library, study rooms, offices and meeting rooms, ateliers, studios, laboratories, and classrooms.
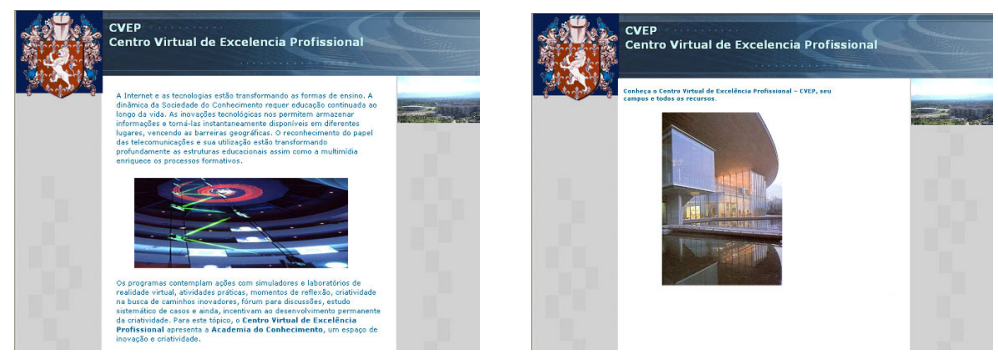

Figure 2: VS. Main entrance.

\subsection{Interaction and methodology}

The activities are designed to develop interpersonal relation between students, creativity to find solutions to case studies or specific problems. Teachers can organize groups of students or "learning communities" to discuss and analyze cases. The interaction encourages students talking about ideas and concepts. The VS create a strongly collaborative team because there are high quality moments of interaction. Chris Dede [1] wrote hundreds articles about knowledge networking and artificial realities. It involves creating a community of mind. Through sharing disparate data and diverse perspectives, a group develops an evolving understanding of a complex topic. Over time, the group's conception of the issues continually expands and deepens, at times broadening the range of fields and experiences seen as relevant. Architecture is a mastery of complex multidimensional information.

The spaces help teachers to organize activities, clear the instructional objectives and goals and present excellent feedback performances. The cultural and interactive activities are supported by tools and resources to go beyond the 
limitation of the self resolutions. Beyond the alone "online students" there are interactive spaces to develop cooperative work. Forums, Galleries of Art, Theatre, and Travel Agency can allow spontaneous encounters with other networked participants, fig 3 .

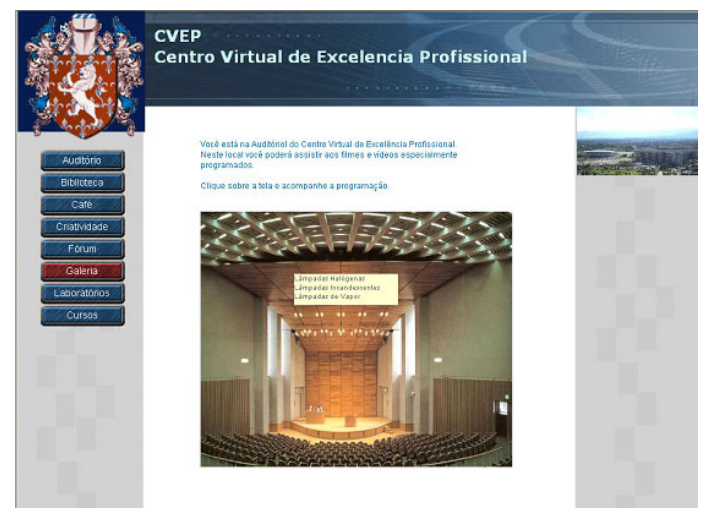

Figure 3: Theatre.

The difference between real and virtual school is the core curriculum. The courses online must be tremendously challenging to these students in order to keep them very motivated. It's necessary to relate theoretical concepts and practical activities. If they do not understand their value or see relationships between these courses and their majors unfortunately they will give up. To improve activities

The Virtual School of Architecture and Design - VS - adopted case methods. This methodology helps students apply theoretical perspectives to real-life situations. A case study is the type of research most applicable to the average students and can be of extreme importance in evaluating system. Because students move from theory to practice, it's allowed learners to connect with their academic values and the knowledge for its practical utility.

In this case study, students are introduced to concepts about techniques and ceramic control. The lesson was designed to teach introductory materials majors about the ceramic tiles in quality control. Working in small groups, the students analyze a variety of information.

They will visit four virtual laboratories to test samples. The technological services offered by the laboratories may be divided into four areas: analyses and testing, finished product laboratory, quality guarantee and information and documentation. The laboratories have appropriate virtual scientific instruments to promote deep understanding about procedures. The finished product laboratory is accredited by certification to carry out standardised testing on ceramic tiles, ceramic materials for construction and sanitary ceramic appliances. Like a real laboratory, the Information and Documentation Unit present the information needs that arise inside and outside the lesson, as a result of the scientific, technological, teaching and training activities carried on. To do this, 
all the documents published about ceramic technology are selected and compiled. With the result they will find multi aspects and they will judge if the floor ceramic tile can be accepted by civil constructors, fig 4 .

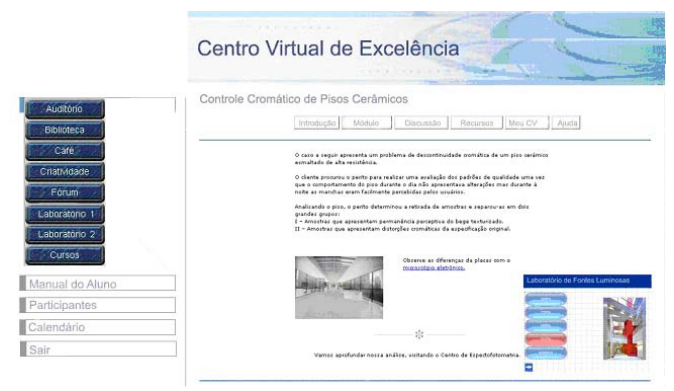

Figure 4: Case study: floor ceramic tiles.

\subsection{Travelling across the History of Architecture}

The internet played a major role in the evolution of society and in the educational process. As a tool for transformation, it improves knowledge beyond geographic boundaries. Disciplines like History of Art, History of Architecture, Urbanism and correlated can visit past and present locations and investigate cultural and technological characteristics.

With Google Earth [2] and similar resources, students can study morphology, geography, topography and landscape. They will take a virtual tour investigating multi aspects about the architecture reference. Teachers can ask students to draw maps of the local area and describing the political and physical boundaries and the reasons why the political boundaries were created in the past and at present times. They can identify the relations between topography and architecture, the city, and the surrounding communities. In the Google Earth map there are links with National Geographic data base [4] and students can investigate many aspects about civilizations, fig 5. Students can read related links and take a tour in Egypt's Ancient History (From the Valley of the Kings to the Great Pyramids to Zigzag in the Delta, discovering fascinating facts about mummies, and other ancient mysteries on the official site of Egypt's Ministry of Tourism and UNESCO) [3].

Several appropriate technologies that can be used, as well as the shortcomings of previous methods. This technology doesn't understand as media through videos and other resources like reality representation, photos in high resolution, realistic environment. Students can manipulate, see different points and details.

In other case, for example Knossos - 3D Virtual Reality Tour, developed by British School of Athens [4] visitors can have full view of interior and exterior of architecture, from every angle and can virtually examine details, fig 6 .

Students can visit Museums and manipulate pottery, sculptures, and objects. Virtual Reality (VR) technologies provide an original resource for enhancing 
user visualization of complex three-dimensional objects and environments. For teachers and architects the acknowledgement that spatial ability is important, it is meaningful to identify the spatial abilities of students. With virtual reality resource they will manipulate sculptures and other museums resources. They can watch specific videos or draw drafts to study details or share sketches. For example, students can understand The Odyssey context examining details in the pottery at Virtual Gallery [5]. With QTVR can Students can manipulate all selected ceramic identifying chapters of the adventure, fig 7.

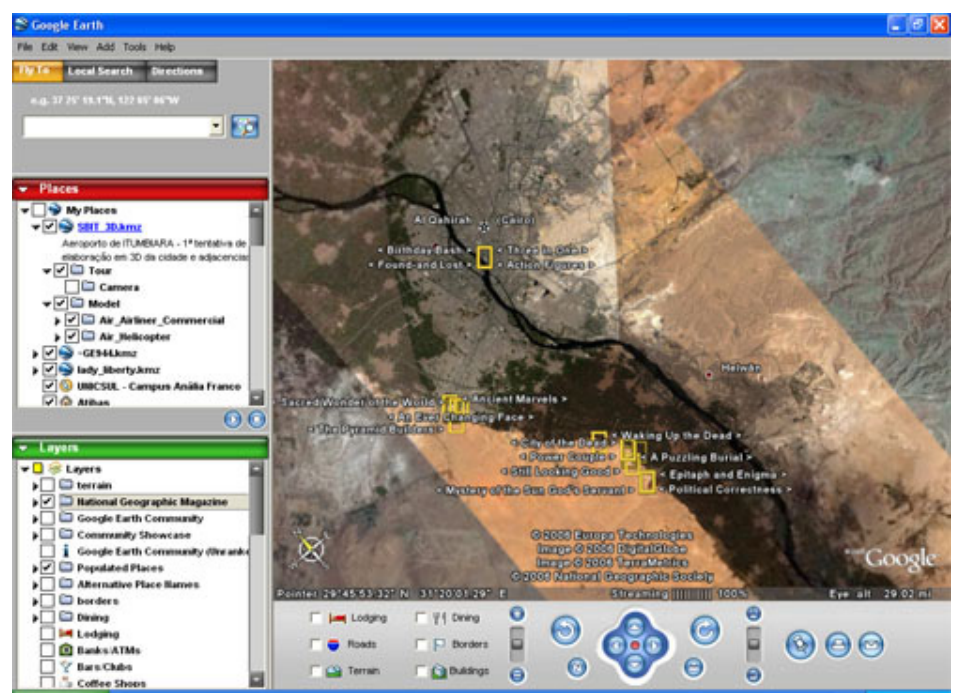

Figure 5: Google Earth - investigating Nile Civilization.

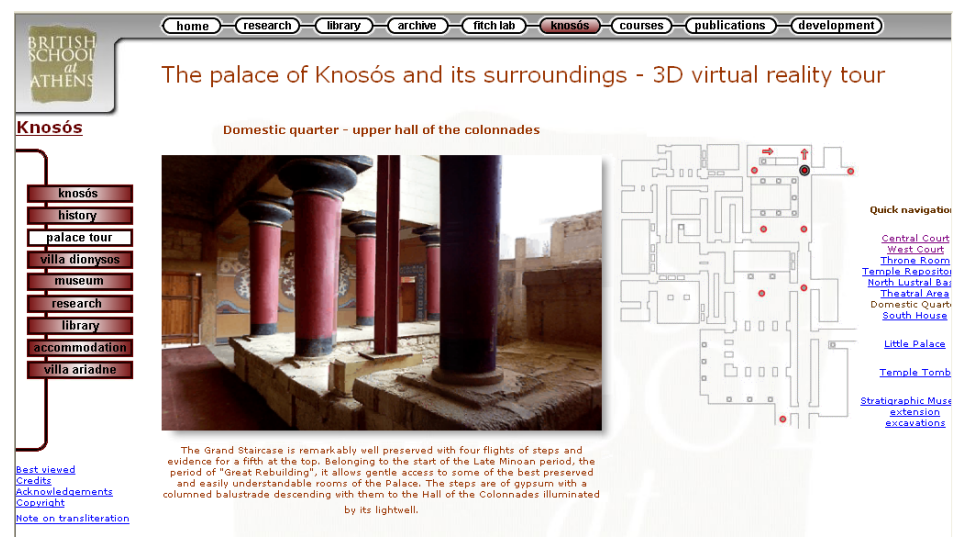

Figure 6: Knossos $-3 \mathrm{D}$ virtual reality tour. 


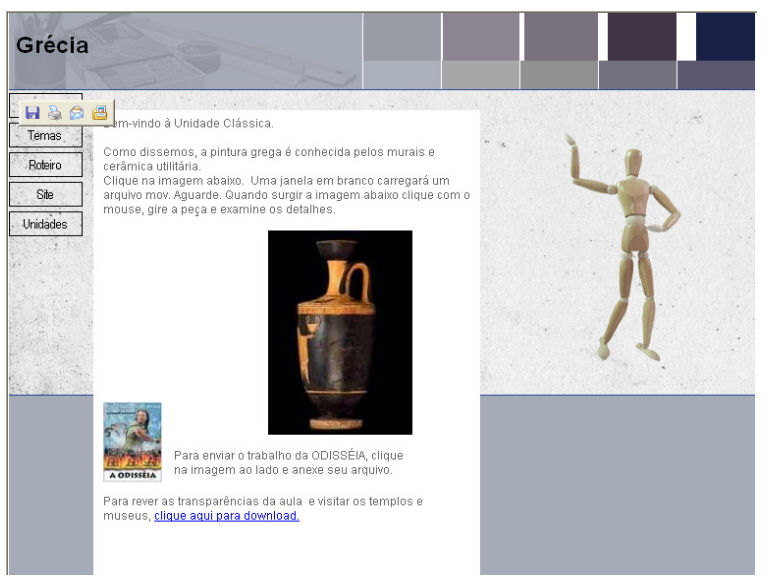

Figure 7: Telling a history about Odyssey.

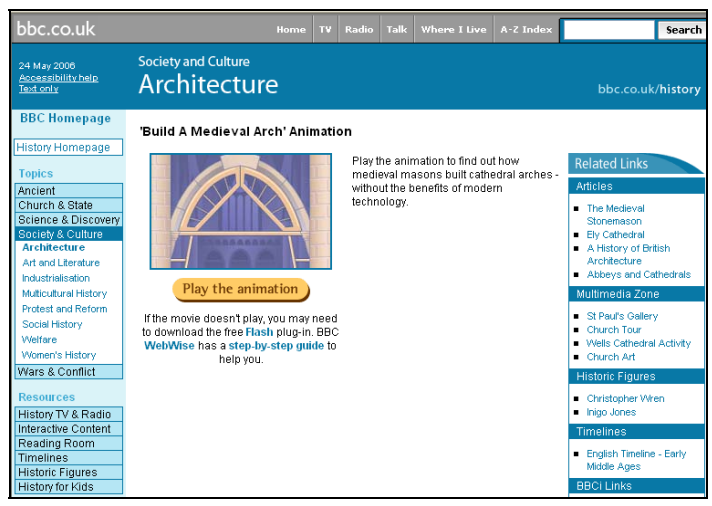

Figure 8: Build a Medieval Arch.

Linking learning objects, students will simulate constructions process. Students can rebuild an arch or understand process and recovering ancient techniques from the past. There are a lot of educational sites and resources like Society and Culture: Architecture from BBC [6]. For example, students can understand how medieval arches were built, fig 8 .

\section{Cultivating creative spirit}

The Architecture and Design environment have been full of innovation. New constructions materials, technologies, whole new civil industries have emerged. Creativity is the historic route to architecture growth. Creativity seems to be useful in any field of life, in arts, science, and business. New ways of thinking that express creative solving of problems is motivated. The pedagogic model of Virtual School is the collaborative learning. Cooperative learning skills promote 
meaningful social interaction through problem solving among students and teachers. Collaborative learning encourages students to take responsibility for their own learning through structured activities, researches and task assignments, and sharing results. According to Gokhale [7], the term "collaborative learning" refers to an instruction method in which students at various performance levels work together in small groups toward a common goal. The students are responsible for one another's learning as well as their own. Thus, the success of one student helps other students to be successful.

\section{Evaluation}

Architecture is inherently multidisciplinary, and the curriculum should also reflect that, and lessons should be integrated with other subjects. The curriculum model engages students in the examination of a real world issue with reference to the seven domains - Arts and Creative Expression, Science and Technology, Physics and Maths, Political Environment, Sociology, Economic and Diversity, Ecology and Environment. Participants seek to show the interrelationships of the domains and the intricate balance of the domains within a given issue.

Grassian [8] presented alternatives to evaluate web sites. It can be adopted by teachers when choose sites linking disciplines in order to find intrinsic value. Assessment models that provide information about each learner's understanding, and based on the way learners respond to questions designed to probe their understanding; teachers can redirect learning activities that correct these errors. Assessments of learning that are consistent with their intended use with multiple meanings. Teachers can recognize results designed to provide feedback that will improve best practices online for new purposes and the type of assessment needs to match its intended use.

\section{Conclusion}

The most important issues identified from the perspective of collaborative learning were that the computer system should facilitate for: mediation of complex collaborative activities such as critical discussion, establishment of a common frame of reference; presentation of individual contributions to a group product; mediation of messages; mediation of activities; organization in division of work; and discussions about results. Several of the lessons as proved to be infeasible in a realistic use situation. This is approached by exploration of the research question: What are the possibilities of internet related to performing collaborative activities in Virtual School of Architecture and Design? Technology available was applied in all pedagogic and research situations. Students need to be able to think creatively, solve problems, present new solutions and make decisions as a team. Therefore, the development and enhancement of critical-thinking skills through collaborative learning is one of the primary goals of technology education.

One important characteristic of this plan is the dissemination of the technology in the faculty. By providing technology that already is familiar to the 
students, the students' efforts related to learning how to use the Virtual School to improve knowledge. Teachers, who all were experienced internet users, found the Virtual School of Architecture and Design system easy to use. The Brazilian participants in the prototyping project, however, had considerable problems related to the telecommunications connections technology (phone or cable access). The internet has yet to penetrate the Brazilian society; a large section of the population does not have access to home computers by cable. The rapid increase of the use of the technology in education, however, is promising in this respect.

\section{References}

[1] Dede, C. Artificial realities, virtual communities, and intelligent artefacts: Implications for engineering education. In J.R. Bourne, A. Broderson, and M. Dawant, Eds., The influence of technology on engineering education (pp. 36-65). Boca Raton, FL: CRC Press.

[2] Google Earth. Online. http://earth.google.com/

[3] Google Earth. Link with National Geographic. Death on the Nile. Online http://magma.nationalgeographic.com/ngm/0210/feature1/index.html.

[4] Palace of Knossos. British School at Athens. Online. http://www.bsa.gla.ac.uk/knosos/index.htm

[5] Understanding Odyssey by Ancient Art. MCG Art Education, Research Institute Online. http://www.marciaholland.com/ha

[6] BBC Society and Culture Architecture http://www.bbc.co.uk/history/ society culture/architecture/launch ani build arch.shtml

[7] Gokhale, A. Collaborative Learning Enhances Critical Thinking http:// scholar.lib.vt.edu/ejournals/JTE/jte-v7n1/gokhale.jte-v7n1.html\#about\%2 Oauthor

[8] Grassian, E. UCLA College Library. Online. http://www.library.ucla.edu /libraries/college/help/critical/index.htm 